УДК 7.036

\title{
МИФОПОЭТИЧЕСКАЯ РЕКОНСТРУКЦИЯ КАК СПОСОБ РАСШИРЕНИЯ ТВОРЧЕСКИХ ВОЗМОЖНОСТЕЙ СОВРЕМЕННОГО ХУДОЖНИКА
}

\author{
Гилёва Марина Алексеевна \\ студент \\ Научный руководитель: Штифанова Евгения Вячеславовна \\ кафедра социальных наук, доцент \\ ФГБОУ ВО «Уральский государственный \\ архитектурно-художественный университет» (УрГАХУ)
}

\begin{abstract}
Аннотация: В статье поднимается проблема формирования авторского стилистического, пластического и тематического языка в творчестве современных молодых художников. В качестве одного из возможных вариантов решения проблемы предлагается метод мифопоэтической реконструкции. Систематизируются основные принципы мифологического мышления, применимые в изобразительном искусстве. Каждый принцип проиллюстрирован примерами из творчества русских или зарубежных художников.

Ключевые слова: молодые художники, поиск творческой индивидуальности, функции мифа, мифологическое мышление, переработка фольклора, мифопоэтическая реконструкция.
\end{abstract}

\section{MYTHOPOETIC RECONSTRUCTION AS A METHOD FOR EXTENDING THE CREATIVE POSSIBILITIES OF MODERN ARTIST}

\section{Gileva Marina Alexeyevna} Scientific adviser: Shtifanova Evgeniya Vyacheslavovna

\footnotetext{
Abstract: The article raises the problem of forming one's own stylistic, plastic and thematic language in the creativity of modern young artists. The method of mythopoetic reconstruction is proposed as one of the possible solutions. The basic principles of mythological thinking applicable in the visual arts are systematized. Each principle is illustrated by examples from Russian or foreign artists.

Key words: young artists, searching for creative individuality, functions of myth, mythological thinking, processing of folklore, mythopoetic reconstruction. 


\section{Введение.}

Мифы питали мировое искусство с давних пор. Так, ещё античные драматурги, поэты, скульпторы начали использовать в своем творчестве мифологические сюжеты. На каждом этапе развития искусства творческие личности по-своему использовали и перерабатывали мифологический материал. Мифологические сюжеты и образы рассматривались как система понятных всем символов и образов, с помощью которой можно было воплощать эстетические идеалы и поднимать проблемы этического характера. Е.И. Ротенберг, один из известных отечественных искусствоведов, пишет: "Художественный образ это всегда типизация действительности, и в такой мере, в какой искусство тяготеет к обобщению, миф всегда привлекателен для художника как первичное и потому наиболее типизированное воплощение главных проблем и коллизий бытия[1]."

В XX веке интерес к мифу возрастает вследствие крушения устоявшейся системы ценностей и смыслов, основ привычного образа жизни, размывания границ истины и реальности. В этих условиях актуальной и полезной стала одна из главных функций мифа - психологическая компенсация [2], создание ощущения обустроенного пространства, которое защищает человека и помогает ему выстроить собственный мир будущего [3]. Из-за этого люди искусства тяготели к мифологии на протяжение всего XX века.

В искусстве XXI века мифологические темы распространены не менее, чем в XX веке. Можно назвать известных художников, обратившихся к культуре и мифологии своего народа - Хамид Савкуев, Зорикто Доржиев. Есть живописцы, которые обыгрывают мотивы мифов разных народов мира, порой достаточно иронично трактуя их в рамках своего стиля - так, например, можно привести в качестве примера А.В.Ремнёва, А.Березовскую, беларусских художников А.С. Изоитко и О. Я. Захаревича; впрочем, этот список можно пополнять ещё долго. Выделяется творчество А.Ю. Новосёлова, где герои мифов не только изображены стильно, оригинально и технично, но обладают какой-то особой проникновенностью и образностью («Ромул и Рем», «Воспитание Ахиллеса», «Тесей и Ариадна»).

Согласно исследованию доцента УрГАХУ Е. С. Нетреба, в творчестве современных молодых живописцев г. Екатеринбурга в последние годы наметилась тенденция к стремлению преодолеть этюдность, сиюминутность впечатлений, обратиться к вечным темам и утвердить непреходящие ценности. Большую роль в творчестве молодых авторов играют размышления об 
историческом прошлом страны, тематические и стилистические отсылки к прошлым эпохам отечественного искусства. Даже портрет становится тематическим и сложносочинённым, приобретает глубокое философское прочтение. Но автор отмечает, что ещё многое предстоит сделать, чтобы молодые авторы сформировали собственный, новый (а значит, современный и актуальный) стилистический, пластический и тематический язык[4].

В данном исследовании предлагается один из возможных вариантов решения проблемы - метод мифопоэтической реконструкции. Помимо помощи в поиске авторского стиля и тематики, мифопоэтическая реконструкция сможет удовлетворить стремление молодых авторов к вечным темам и философскому содержанию. Новизна предлагаемого метода заключается в том, что использование мифопоэтической реконструкции в изобразительном искусстве рассматривается с точки зрения автора - художника, а не искусствоведа или культуролога. Это позволяет сделать работу как можно более приближенной к практическому использованию другими художниками.

Процесс функционирования мифа в различных видах искусства протекает со своими нюансами, вызванными спецификой данного вида искусства, но в целом изучение литературы по теме показало, что как во временных, так и в пластических искусствах взаимодействие с мифом протекает сходным путём. Из этого следует, что результаты исследований в сфере литературы могут быть применимы и к изобразительному искусству. Интерес представляет система С.М. Телегина, предлагающего термин «мифореставрация». Исследователь разделяет мифореставрацию на три направления: заимствование мифологических сюжетов и образов; создание собственной системы мифов; реконструкция мифологического сознания. В данной работе мы рассмотрим направление реконструкции мифологического сознания, или мифопоэтической реконструкции.

\section{Основная часть.}

Существуют разные точки зрения на то, сознательно или бессознательно люди творческих профессий обращаются к мифу, но всё же преобладает мнение о том, что мифотворчество является в большей степени сознательным актом. Это подтверждает возможность практического применения этого метода современными художниками. Согласно исследованию Г. А. Токаревой [2], в процессе мифореконструкции происходит «сознательное обращение к бессознательному». Данный метод подобен ролевой игре, участники которой полностью вживаются в роль. В большинстве случаев сам акт работы над 
произведением в первую очередь важен для художника, который повторяет мифологический процесс создания своей вселенной (по С. П. Батраковой псевдоритуальное воспроизведение мифа творения [5]).

Несмотря на то, что «чистая...модель мифологического мышления, вероятно, не может быть документирована» [6], исследователи, пользуясь методом этнологической, культурологической и лингвистической реставрации, а также на основе изучения детского мышления, соотносимого с мифологическим, постарались восстановить основные принципы мифологического мышления. Вот те принципы, которые применимы в изобразительном искусстве:

1) Диффузность сознания[8] — неразделенность субъекта и объекта, субъекта и его признаков, идеального и реального, естественного и сверхъестественного, вещи и ее свойства, социума и космоса, человека и вселенной; «То, что с точки зрения немифологического сознания различно, расчленено, подлежит сопоставлению, в мифе выступает как вариант (изоморф) единого события, персонажа, текста» [9]. Этот признак выражается формулой «всё во всём» [5];

Художественную практику русского авангарда можно рассмотреть как яркий пример воспроизведения модели мифологического мышления с акцентом на диффузности сознания. Немаловажную роль в формировании русского авангарда сыграл русский космизм (совокупность течений философской и религиозной мысли, ставящих в центр своих исследований проблему космического всеединства всего живого, волю к мистико-интуитивному познанию внеземных пространств [10]). Благодаря космизму в русском искусстве на рубеже XIX - XX веков распространились идеи религиозно-мистической связи человека и космоса, единства человека и природы, синтеза и взаимодействия всех сфер искусства.

Один из самых известных представителей русского авангарда К.С. Малевич, основатель направления, названного им «супрематизм». Философским ориентиром теории Малевича стал тезис учения В.С. Соловьева - всеединство как преодоление раздробленности мирового организма. В 1920 году Малевич призывает освободиться от таких предрассудков, как «родина, патриотизм и отечество», национализм и самоопределение народов», во имя «супрематии единства человечества» и «стремиться к единому языку, к единодейству духовному». «Идя по супрематическому пути, мы сможем освободить разорванный, растерзанный образ, распластанный, распятый пятью частями нашей земли[11]...» 
В своей книге «От кубизма и футуризма к супрематизму» он изложил суть супрематизма: художник должен творить форму, естественным путём выходящую из живописных масс, с помощью «интуитивного разума» «оформляет тело» цвета. «...Такие формы (супремы) не будут повторением живущих вещей в жизни, а будут сами живой вещью»[12]. В более поздних этапах творчества К.С. Малевич разрабатывает тему слияния человека с супрематическим универсумом, создаёт живописный миф единения человека со Вселенной, наполовину растворяя фигуры в фоне.

Таким образом, К.С. Малевич в своей теории, во-первых, одушевляет картину, во-вторых, соединяет в одно форму, содержание и саму картину как материальный объект, и, в-третьих, утверждает супрематизм как язык, способствующий восстановлению единства человечества и его духовному преображению путём создания и созерцания чистых супрематических форм.

2) Бриколаж - нестандартная связь чего-либо с чем-либо, причина этой связи неочевидна и часто противоречит формальной логике. Название произошло от французского термина, который у игроков в бильярд обозначает неожиданный отскок шара, а в верховой езде - непредсказуемое поведение лошади. Антрополог К. Леви-Стросс впервые использовал этот термин для описания специфики и структуры мифологического мышления. В жизни человека эпохи культурной архаики или современных племён, сохранивших традиционный общественный уклад и верования предков, находилось немало вещей, иллюстрирующих бриколажную логику - к примеру, отождествление людей определённого племени со своим тотемным животным, или проведение обрядов, по убеждению данной общины, способствующих богатому урожаю, удачной охоте и пр.

В процессе бриколажа средства не подчинены цели, скорее напротив: направленность мысли определяется рекомбинацией, на манер калейдоскопа, образов-символов, сформировавшихся во время прошлого опыта, причём в процессе рекомбинации элементов именно прежние цели играют роль средств. В современном мире бриколаж из архаичного способа познания мира превратился в творческий приём, с помощью которого художник преодолевает ограничения логического мышления и находит нестандартные и узнаваемые образы.

Метод бриколажа можно рассмотреть на примере творчества бельгийского художника-сюрреалиста Рене Магритта. Магритт не просто использует обыденные предметы, окружающие его современника, он отбирает наиболее простые вещи, из которых выстраивает свои работы-ребусы: яблоко, яйцо, птица, 
клетка, трубка, тромбон, мольберт, и, конечно, ставший «визитной карточкой» наследия Магритта мужской силуэт в котелке и чёрном пальто, символизирующий, по словам художника, «человека среднего класса, спрятанного в своей анонимности». Местом действия чаще всего является обобщённый условный сад или берег моря, песчаный или скальный, или пустая комната (чаще - фрагмент с окном и плотными шторами). Но благодаря неожиданным метафорическим комбинациям этих элементов творчество Магритта стало известным во всём мире.

По свидетельству художника, для того, чтобы найти сюжет для картины, он брал произвольный предмет и начинал «решать его теорему» с помощью поиска другого объекта, который связан с ним какими-либо нестандартными, неочевидными общими признаками. Таким образом, связь «предмета-вопроса» и «предмета-ответа» в результате даёт смелую и запоминающуюся живописную метафору. Подобный ход творческого процесса можно уподобить бриколажу.

Так же можно назвать и принцип, по которому Магритт подбирал названия работ. Следует отметить, что названия для Магритта были не просто формальным опознавательным знаком, но неотъемлемым элементом, взаимодействующим с картиной, влияющим на её восприятие и открывающим новые смыслы. Самый известный пример - работа «Это не трубка». Название не только не объясняло того, что происходит на картине, но порождало ещё больше вопросов.

Так, в одном из своих писем Магритт рассказывает о работе над картиной «Каникулы Гегеля». Вначале он поставил себе цель: изобразить стакан воды гениально. После того, как художник счёл, что добился цели, он подумал, что этот предмет смог бы заинтересовать Гегеля - Гегель был гением, стакан изображён гениально, значит, у них есть сходство. По утверждению Магритта, Гегель мог бы подумать над этим в свободное время, к примеру, на каникулах. Так родилось броское и неожиданное для зрителя название, провоцирующее зрителя на размышления.

3) Антропоморфизм - перенос свойств человеческой природы на предметы и явления окружающего мира. В изобразительном искусстве может выражаться в создании антропоморфных персонажей.

4) Кумулятивный принцип (по В. Проппу) представляет собой присоединение, нагромождение или нарастание образных элементов. Кумулятивность называют характерной особенностью фольклорных композиций, детского мышления и мифологического мировосприятия. «Нанизывание есть не 
только художественный приём, но и форма мышления вообще, сказывающаяся не только в фольклоре, но и на явлениях языка» [15].

Среди инструментов творческого самовыражения Марка Шагала миф занимал особое место. Мифологическое мышление художника было сформировано под влиянием культуры хасидов (хасиды — последователи одного из течений иудаизма, в котором делается акцент на ощущении присутствия Бога в мире, эмоциональном, экстатическом религиозном переживании) с eе пантеистическим представлением о природе и мире, а также искусства русского модерна и авангарда, ориентированных на новый мифологизм[16]. С помощью творческого наследия Марка Шагала можно проиллюстрировать антропоморфизм и кумулятивный принцип.

Приём кумулятивного построения картины можно увидеть во многих работах современников Шагала, например, С Дали, М. Эрнста, даже некоторых композициях П. Пикассо. Но у Шагала присоединение, «нанизывание» можно назвать основным композиционным приёмом. Вокруг главного героя или композиционной доминанты (если её можно выделить) в хаотическом порядке располагаются характерные для Шагала образы-символы - коза, петух или курица, рыба, влюблённая пара, музыканты и цирковые артисты, витебский пейзаж; эти объекты могут быть даже «налеплены» друг на друга, один элемент служит фигурой сам по себе и фоном - для другой фигуры. В отличие от Магритта, чьё комбинирование типичных для него образов - решение, по выражению художника, "теоремы двери" или любого другого предмета, нестандартные логические ходы в игре с предметами, благодаря которым они приобретают другой смысл, образы Шагала нанизываются друг на друга, не меняя содержания. Он может объединить в одном персонаже еврея-скрипача и козу, дополнить образ крыльями, и всё же мы видим не нового цельного героя, а одновременно слагаемые и сумму.

Художник органично вписывает животных в мир людей, уравнивая их в значимости. Они могут обладать явной антропоморфностью, к примеру, рыба с руками, коза в костюме; помимо этого, у всех животных, рыб и птиц Шагала человеческие глаза и они ведут себя как люди, к примеру, держат зонтик или свечу, играют на скрипке. Стоит отметить пограничный вариант, когда изображены скорее зооморфные люди с куриной или козьей головой.

5) Специфическое строение пространственно-временной модели мира.

Пространство мифа характеризуется парадоксальным сочетанием дробности (Ю. Лотман и Б. Успенский говорят о «лоскутном характере 
мифологического пространства» [6]) и однородности (засчёт отождествления мира с человеческим телом и его частями, пространственно-физического соответствия между миром и человеком). Оно упорядочивается через систему бинарных оппозиций (верх-низ, право-лево, сакральное и профанное, свет и тьма); центром пространства мыслится некая точка или линия (ось), приобретающая различные формы: гора, дерево, столп, при этом понятия «центр» и «периферия» обнаруживают свою относительность в силу универсальной идеи изоморфизма (тождества, идентичности - см. пункт 1).

Время мифа циклично: событие, происходящее в данный момент, одновременно происходит «в первовремени», в категории «всегда», возвращается к истоку. [2]

В данной статье мы рассмотрели принципы мифологического мышления в качестве максимально доступной для молодого художника теоретической базы, которая поможет ему в использовании мифопоэтической реконструкции. Но нельзя сказать, чтобы метод сознательной мифопоэтической реконструкции ещё не был освоен; в качестве примера можно упомянуть творчество современного художника В. И. Фуфачёва и его арт-проект «Мастерская Фуфачёва», более 15 лет назад организованный в Нижнем Новгороде. Искусствовед Е. Н. Крюкова в аннотации к выставке «Мастерская Фуфачёва: путь к себе»[19] пишет, что В. И. Фуфачёв, обращаясь к пластическим, колористическим и образным достижениям прошлых веков, движется к созданию собственного мифа и авторской символики, возрождает древние символы-знаки и мифологемы в современном арт-пространстве. В творчестве художников, работающих с ним в арт-проекте, также присутствует попытка конструирования собственной философской системы, а наиболее интересные образы претендуют на то, чтобы стать новыми мифологемами.

Довольно крупным явлением в искусстве начала XXI века является сибирская неоархаика («этноархаика», «археоарт») — направление, основанное на анализе и синтезе культурного наследия и мифологии древних цивилизаций Сибири. Направление включает в себя художников территорий Байкальского региона, Алтая, Тывы, Западно-сибирской степной и таежных зон, Ханты Мансийского и Ямало-Ненецкого округов. Произведения художников этого направления насыщены мифологическими и архаическими мотивами, образами, символами и знаками. Сибирской неоархаике посвящена статья А. Г. Кичигиной «Мифологемы в искусстве неоархаики»[18], в которой выявляются свойства мифологического сознания в художественно-образной структуре этого 
направления. Автор выделяет синкретизм(у нас - диффузность сознания), хронотопичность и систему бинарных оппозиций(в нашей статье эти два признака объединены в «специфическое строение пространственно-временной модели мира»), а так же бриколаж и метафоричность(её можно считать следствием бриколажа). Следует заметить, что данная статья была найдена уже на завершающем этапе исследования, поэтому все совпадения случайны; впрочем, в ней каждому свойству уделяется один-два кратких абзаца, не проиллюстрированных описаниями творчества конкретных авторов, а описание бриколажа и вовсе отсутствует. Тем не менее, статья А. Г. Кичигиной доказывает возможность успешного применения свойств мифологического сознания в творчестве современных художников.

\section{Заключение.}

Мифотворчество как постоянно развивающийся символический язык, с помощью которого человек определяет своё место в мире и сам мир, значительно разнообразило средства выразительности. Мифопоэтическая реконструкция внесла в искусство новаторские композиционные, живописные и пластические приёмы, смелость неожиданных ассоциаций и творческую переработку традиций древних культур. Этот опыт может быть использован художниками XXI в. для поиска своего изобразительного языка и творческого пути.

\section{Список литературы}

1 .Ротенберг Е.И. Западноевропейская живопись 17 века. М., 1989.

2. Токарева Г. А. Мифопоэтика У. Блейка. Петропавловск-Камчатский, изд-во КамГУ, 2006, 350 с.

3. Кубанова Т.А. Преемственность в изобразительном искусстве: искусство и миф (Анализ публикаций первого десятилетия XXI века). // Личность и художественный процесс : к 75-летию Г. С. Райшева : материалы научно-практической конференции, 17-18 ноября 2009 / Департамент культуры и искусства Ханты-Мансийского авт. округа - Югры, Галерея-мастера худож. Г. С. Райшева, Художественная галерея Фонда поколений ; [отв. ред. Н. Н. Фёдорова]. - Ханты-Мансийск : Полиграфист, 2009. - 129 с

4. Нетреба Е.С. Анализ участия молодых художников-живописцев екатеринбурга в межрегиональных выставках ВТОО СХР «Урал» [Электронный ресурс] / Е.С. Нетреба //Архитектон: известия вузов. - 2020. - №4(72). - URL: http://archvuz.ru/2020_4/19/- doi: 10.47055/1990-4126-2020-4(72)-19 
5. Батракова С.П. Искусство и миф: из истории живописи XX века. М., Наука, 2002.

6. Лотман Ю. М. Успенский Б. А. Миф - имя - культура / Ю. М. Лотман, Б. А. Успенский // Лотман Ю. М. Семиосфера. - СПб.: Искусство, 2000. - С. 525543

7. URL: https://depcultura.admhmao.ru/yubiley-yugorskogo-khudozhnika-g-sraysheva/2565538/statya-gorizonty-prostranstv-gennadiya-raysheva

(Дата обращения - 25.01. 2021)

8. Мелетинский Е. М. Поэтика мифа. / Е. М. Мелетинский. - М.: Восточная литература РАН, 1995. - 408c

9. Лотман Ю., Минц 3., Мелетинский Е. Литература и миф / Ю. Лотман и др. // Мифы народов мира. Энциклопедия в 2 т. - М : Олимп, 1997. - Т. 2. - С. 5965 .

10. Большой Энциклопедический словарь онлайн URL: https://rus-newphilosophia-enc.slovaronline.com/351-русский_космизм (Дата обращения 24.01. 2021)

11. Парфёнова А. И. Влияние философии космизма на русскую культуру конца XIX - начала XX века. Диссертация на соискание степени кандидата культурологии по направлению 24.00.01. «теория и история культуры», СПбГУКИ, Санкт-Петербург, 2001. - 168 с

URL: $\quad$ https://www.dissercat.com/content/vliyanie-filosofii-kosmizma-narusskuyu-kulturu-kontsa-xix-nachala-xx-veka (Дата обращения — 23.01. 2021)

12. Малевич К. От кубизма и футуризма к супрематизму. - М., 1916. - С. 22.

13. Леви-Стросс К. Первобытное мышление.- М.: Республика, 1994.— 384 c.

14. Бернар Н. Магритт. М., Слово/Slovo, 1995

15. Пропп В.Я. Поэтика фольклора. - М. : Лабиринт, 1998. - 352 с.

16. Сульянова Д. В. Проблема мифа в творчестве Марка Шагала (на примере "Библейского послания"). Диссертация на соискание степени магистра по направлению 50 (Дата обращения - 24.01. 2021) .04.03 «история искусств», СПбГУ, Санкт-Петербург, 2017 URL: https://revolution. allbest.ru/culture/00842652_1.html

17. URL: http://www.aggregateria.com/L/lotman.html\#: :text $=$ ЛОТМАН $\%$ 20Юрий\%20Михайлович\%20(1922\%20-,числе\%20c\%20точки\%20зрения\%20 семиотики) (Дата обращения - 14.04. 2021) 
18. Сибирская неоархаика. Сборник материалов. Отв. редактор В.Ф. Чирков. Сост.: В. Ф. Чирков, О. М. Галыгина. Новокузнецк, 2011. - 124 с.

19. URL: http://www.shr-ekb.ru/exibitions.php?exid=366 (Дата обращения 14.04. 2021)

\section{Bibliography}

1 .Rotenberg E.I. Zapadnoevropeřskaya zhivopis' 17 veka. M., 1989.

2. Tokareva G. A. Mifopoetika U. Blejka. Petropavlovsk-Kamchatskij, izd-vo KamGU, 2006, 350 s.

3. Kubanova T.A. Preemstvennost' v izobrazitel'nom iskusstve: iskusstvo i mif (Analiz publikacij pervogo desyatiletiya XXI veka). // Lichnost' i hudozhestvennyj process : k 75-letiyu G. S. Rajsheva : materialy nauchno-prakticheskoj konferencii, 17-18 noyabrya 2009 / Departament kul'tury i iskusstva Hanty-Mansijskogo avt. okruga - YUgry, Galereya-mastera hudozh. G.S. Rajsheva, Hudozhestvennaya galereya Fonda pokolenij ; [otv. red. N.N. Fyodorova]. - Hanty-Mansijsk : Poligrafist, 2009. - $129 \mathrm{~s}$

4. Netreba E.S. Analiz uchastiya molodyh hudozhnikov-zhivopiscev ekaterinburga v mezhregional'nyh vystavkah VTOO SKHR «Ural» [Elektronnyj resurs] /E.S. Netreba // Arhitekton: izvestiya vuzov. - 2020. - №4(72). - URL: http://archvuz.ru/2020_4/19/- doi: 10.47055/1990-4126-2020-4(72)-19

5. Batrakova S.P. Iskusstvo i mif: iz istorii zhivopisi XX veka. M., Nauka, 2002.

6. Lotman YU. M. Uspenskij B. A. Mif - imya - kul'tura / YU. M. Lotman, B. A. Uspenskij // Lotman YU. M. Semiosfera. - SPb.: Iskusstvo, 2000. - S. 525-543

7. URL: https://depcultura.admhmao.ru/yubiley-yugorskogo-khudozhnika-g-sraysheva/2565538/statya-gorizonty-prostranstv-gennadiya-raysheva

(Data obrashcheniya - 25.01.2021)

8. Meletinskij E. M. Poetika mifa. / E. M. Meletinskij. - M.: Vostochnaya literatura RAN, 1995. - 408s

9. Lotman YU., Minc Z., Meletinskij E. Literatura i mif / YU. Lotman i dr. // Mify narodov mira. Enciklopediya v 2 t. - M : Olimp, 1997. - T. 2. - S. 59-65.

10. Bol'shoj Enciklopedicheskij slovar' onlajn URL: https://rus-newphilosophia-enc.slovaronline.com/351-russkij_ kosmizm (Data obrashcheniya 24.01. 2021)

11. Parfyonova A. I. Vliyanie filosofii kosmizma na russkuyu kul'turu konca XIX - nachala XX veka. Dissertaciya na soiskanie stepeni kandidata kul'turologii po 
napravleniyu 24.00.01. «teoriya i istoriya kul'tury», SPbGUKI, Sankt-Peterburg, 2001. - $168 \mathrm{~s}$

URL: $\quad$ https://www.dissercat.com/content/vliyanie-filosofii-kosmizma-narusskuyu-kulturu-kontsa-xix-nachala-xx-veka (Data obrashcheniya - 23.01. 2021)

12. Malevich K. Ot kubizma i futurizma k suprematizmu. - M., 1916. - S. 22.

13. Levi-Stross K. Pervobytnoe myshlenie.-M.: Respublika, 1994.— $384 \mathrm{~s}$

14. Bernar N. Magritt. M., Slovo/Slovo, 1995

15. Propp V.YA. Poetika fol'klora. - M. : Labirint, 1998. - $352 \mathrm{~s}$.

16. Sul'yanova D. V. Problema mifa v tvorchestve Marka SHagala (na primere "Biblejskogo poslaniya"). Dissertaciya na soiskanie stepeni magistra po napravleniyu 50.04.03 «istoriya iskusstv», SPbGU, Sankt-Peterburg, 2017 URL: https://revolution.allbest.ru/culture/00842652_1.html (Data obrashcheniya - 24.01. 2021)

17. URL: http://www.aggregateria.com/L/lotman.html\#: :text=LOTMAN\% 20YUrij\%20Mihajlovich\%20(1922\%20-,chisle\%20s\%20tochki\%20zreniya\% 20semiotiki) (Data obrashcheniya - 14.04. 2021)

18. Sibirskaya neoarhaika. Sbornik materialov. Otv. redaktor V.F. CHirkov. Sost.: V. F. CHirkov, O. M. Galygina. Novokuzneck, 2011. - 124 s.

19. URL: http://www.shr-ekb.ru/exibitions.php?exid=366 (Data obrashcheniya $-14.04 .2021)$

(C) М.А.Гилёва, 2021 